processes to the species. Kesearch has shown that the cost of chemicals required for pulping the grass by the mono-sulphite process is 38 per cent more than that required by the soda process. Of the two methods of digestion, namely, 'overhead' and 'fractional', as applicable to the soda process, the 'fractional' method of digestion appears to be more suitable, as well as more economical, for pulping of illuk grass.

In Indian Forest Leaflet No. 124 of the Research Institute*, R. V. Bhat and N. S. Jaspal discuss investigations on pulps for writing and printing papers from the castor oil plant (Ricinus communis). In India, so far, bamboo and sabai grass (Eulaliopsis binata) are the chief raw materials used in the paper industry. The local supplies of these materials are insufficient to meet the requirements of the existing mills. Bamboos are used in India for a large variety of other purposes, and the sabai grass only grows in particular areas. The production of paper in Indian mills in 1949 amounted to 170,000 tons. To meet domestic demands for paper, a large quantity is annually imported, and these demands are increasing. The instalment of further new pulp plants depends upon larger amounts of raw material being available.

Reimold had advocated the cultivation of the castor oil plant in America, as a high-grade cellulose could be produced at a low price owing to the cheapness of the raw material. The castor oil plant is commonly grown as an annual crop in several parts of India for its seeds, from which the oil is obtained, and it is upon the stalks, for the purpose of making pulp, that experiments were made at Dehra Dun. The plant is also grown as a perennial small tree, and this, too, was the subject of research work.

The conclusions arrived at are as follows. Easybleaching pulps with satisfactory strength properties can be prepared from stems of castor oil plants by the soda and the sulphite processes, the latter being the more suitable. 'The stems of the annual and the perennial varieties can be used for pulping without the removal of the bark. The pulps from the wood are short-fibred, whereas those from the bark are long-fibred. Owing to this, pilot-plant experiments will have to be carried out to determine whether these pulps can be used as such for the production of writing and printing papers or whether they must be mixed with long-fibred pulps such as those from bamboos and sabai grass. Since in India the castor oil plant is grown for its seeds and oil production, it is considered that the stalks should be available at a cheap rate.

* Indiar Forest Leaflet No. 124: Indigenous Cellulosic Raw Materials for the Production of Pulp, Paper and Board. Part 2 Pulps for Writing and Printing Papers from the Castor Oil Plant Ricinus communis. By Dr. R. V. Bhat and Narendra S. Jaspal. Pp. ii +15 . (Delhi: Manager of Publications, 1951.) Annas 8; $9 \dot{d}$.

\section{ORNITHOLOGY IN THE U.S.S.R.}

$\mathrm{T}$

HE ornithology of the U.S.S.R. has been somewhat imperfectly known in other countries, especially of recent years. On behalf of the British Ornithologists' Union, Dr. Hans Johansen, formerly professor in the University of Tomsk and now of the Zoological Museum, Copenhagen, has prepared a paper which attempts to review the place of ornithological studies in the U.S.S.R. to-day (Ibis, 94, No. 1). Johansen's task has not been easy because no journal devoted entirely to ornithology has been published in the U.S.S.R.; some of the publications containing ornithological articles are unobtainable. Information about articles on ornithology can frequently only be obtained through lists of Russian literature, so that the articles cannot be seen or judged on merit. Although Johansen's survey must, therefore, necessarily be regarded as incomplete, the author is to be commended for undertaking a task which has involved consideration of not less than five hundred publications.

A summary of Johansen's article indicates that the old traditions of Russian ornithology were best and most strongly represented by faunistic reviews which have almost completely surveyed the whole of the enormous country. Large amounts of material were collected in the form of bird-skins, which made possible the systematic revision of many groups of birds. This again made possible broad concepts of the avifauna of the U.S.S.R. as a whole and the numerous zoogeographical and historical faunistic descriptions.

In addition to these old branches of work, new problems have arisen in recent times, as in the rest of the world. Of these, biological and ecological subjects are prominent and, among other things, have led to the production of ecological-geographical monographs on the birds of Russia.

Many investigations have also been made into the problems of bird migration; in addition to ringing and field observations, laboratory experiments have been made, with good results.

Some work has been done on anatomy and physiology in which attempts were made to connect them with biology, ecology and systematics. Investigations on parasites as well as the disadvantages and benefits of birds to forestry and agriculture were specially supported by the authorities.

If the accomplishments of the Russian ornithologists are considered from a wider and more international point of view it can be said that, on the whole, development has proceeded on the same lines as in other countries, though studies naturally show the peculiar influence of the country.

Because of the great extent of the country, from the Baltic to the Pacific Ocean and from high polar latitude to the subtropical conditions in the Transcaucasus, Russian ornithologists have done little work outside their own country. There is, however, the work of Zarudny in Persia and the numerous Russian expeditions made long ago in Mongolia and central Asia. In recent times these works were continued by Sushkin, Tugarinov, Sudilovskaia (Kashgaria) and, more especially, by Madame Kozlova.

The extent and variation of the U.S.S.R. have also been the reason why the so-called line of faunistic research has received special attention. In recent times, according to Russian information, the emphasis has shifted to ecological-geographical characteristics of entire taxonomic groups of birds. This can be regarded as a new branch of Russian ornithology, though publications have not been received in other countries.

Another speciality of Russian ornithology, which was started by Nikolai Severtzov so long ago as 1877 , is the profound zoogeographical analysis, which was chiefly combined with historical conclusions. Of the latest achievements, Stegmann's work on the ornithogeographical division of the Palæarctic Region can claim originality, since he provides new methods and techniques of zoogeographical description. 